\title{
Geographic Information Systems (GIS) As an Indispensable Tool for Environmental Impact Assessment (EIA)
}

\author{
Eta J. B., Adepoju M. O., Halilu, S. A., Mohammed, S. O., Adeluyi, S. A. \\ Department of Strategic Space Applications, National Space Research and Development Agency, Abuja, \\ Nigeria.
}

\begin{abstract}
GIS is rapidly becoming widely known and utilised and has started to promote "spatial thinking" throughout impact assessment processes. The use of crosscutting edge technology with great capacity to handle enourmous spatial and aspatial datasets for great analytical swiftness of a GIS. Due to the over dependence of EIA on spatial data, the conventional way of carrying out an EIA study is considered less accurate and a more time consuming process because of the myriad of dependent and independent variables that always have to be taken into consideration (e.g. Land use, land price, population density, socio-economic level, road accessibility, railway accessibility, air quality, ground water quality, noise level, biological content, historical value, archaeological and visual importance), which will all have different consequences. Thus, it has become imperative to find tools that will complement the process, a tool that is capable of handling large volumes of spatial and non-spatial data and is also capable of handling the very complex analyses that EIA requires. The application of GIS/RS reduces the tediousness of the entire process and provides scientific bases for monitoring of large areas with projects or programmes that have large spatial coverage. For instance, mechanised farming, urbanisation, oil pipeline transportation, deforestation, industrial park establishment, new town development etc. are better assessed and monitored to complete the EIA procedure by UNEP. Geographic Information Systems and Remote Sensing have been adopted and utilized in the developed countries to produce mисh more accurate results and perform various geographic analyses even in complex situations. This paper explored the applications of Geographic Information Systems and Remote Sensing as an indespensable tool for Environmental Impact Assessment Procedures.
\end{abstract}

Keyword: Environmental Impact Assessment, Geographic Information Systems, Spatial Database Management, Remote Sensing, Monitoring

\section{Introduction}

Environmental degradation and ecological deterioration in the past century, with little or no real solution to alleviate many of these concerns have been the major conundrum in many developing countries (Bhatt, 2009[1]) and it is no surprise that human interference is the major contributor to this. It is as a result of the constant development the world over that several countries decided to adopt Environmental Impact Assessment (EIA) as a decision making tool to ensure that development occurs with very little negative impacts to its immediate environs. EIA was first established in the United States in the National Environmental Policy Act of 1969. EIA process has rapidly increased over time and is today being practiced in more than 100 countries in the world (Yousefi, 2004[2]). The EIA tool is used worldwide as an instrument for developmental planning and control, in an effort to anticipate and quantify the socio-economic and biophysical changes that may result from a proposed project. EIA is one of the older and most institutionalised procedures, and refers primarily to the environmental assessment of project level interventions.

Due to the over dependence of EIA on spatial data, the conventional way of carrying out an EIA study is considered less accurate and a more time consuming process because of the myriad of dependent and independent variables that always have to be taken into consideration (e.g. Land use, land price, population density, socio-economic levels, road accessibility, railway accessibility, air quality, ground water quality, noise level, biological content, historical value, archaeological and visual importance), which will all have different consequences (Muthusamy and Ramalingam, 2003[3]). Thus, it has become imperative to find tools that will complement the process, a tool that is capable of handling large volumes of spatial and non-spatial data and is also capable of handling the very complex analyses. This in the long run will reduce the tediousness of the entire process. Tools such as Geographic Information Systems and Remote Sensing have been adopted and are known to produce much more accurate results and perform various geographic analyses even in complex situations. GIS is rapidly becoming widely known and utilised and has started to promote "spatial thinking" throughout the impact assessment processes (Campo, 2012[4]). 


\section{Environmental Impact Assessment}

Yousefi (2004[2]) defined EIA as a process for identifying, predicting, evaluating and mitigating the biophysical, biological, hydrological, ecological, meteorological, noise, economical, social, and other relevant effects prior to development, then using the conclusions as a tool in planning and decision-making. In other words, impact assessment, simply defined, is the process of identifying the future consequences of a current or proposed action. Environmental Impact Assessment (EIA) is a procedure of a systematic investigation of both positive and negative impacts on the physical, biological and socioeconomic environment, which would be caused or induced due to a proposed developmental project (Agrawal and Dikshit, 2002[5]). Its primary objective is to encourage the inclusion of environmental considerations in planning and decision making and to ultimately arrive at actions that are more environmentally attuned.

During an EIA exercise, the environmental consequences of projects are identified and assessed before authorisation is given to the project. The assessment could lead to making modifications to the project, for example to mitigate or reduce the expected impact on the environment. Public involvement is a key element of the EIA procedure. The public is informed of the decision afterwards. The process involves an analysis of the likely effects on the environment, recording those effects, undertaking a public consultation exercise, and taking into account comments from the public. After which a final decision is reached and the public is sensitised to that effect.

The International Association for Impact Assessment adopts the following steps as being part of an EIA process: screening, scoping, examination of alternatives, impact analysis, mitigation and impact management, evaluation of significance, preparation of environmental impact statement (EIS) report, review of the EIS, decision making and follow up. And to elaborate further Muthusamy and Ramalingam (2003[3]) agree that an ideal EIA system would

- Apply to all projects that are expected to have a significant environmental impact and address all impacts that are expected to be significant.

- Compare alternatives to a proposed project (including the possibility if not developing sites) management technique and mitigation measure.

- Result in a clear EIS which conveys the importance of the likely impacts and their specific characteristics to non-experts as well as experts in the field.

- Include broad public participation and significant administrative review procedure.

- To be timed so as to provide information for decision- making

- Be enforceable

- Include monitoring and feedback procedures

In all of these steps mentioned, Geographical Information Systems can play a pivotal role in ensuring that the steps are timely, efficient and as accurate as possible. 


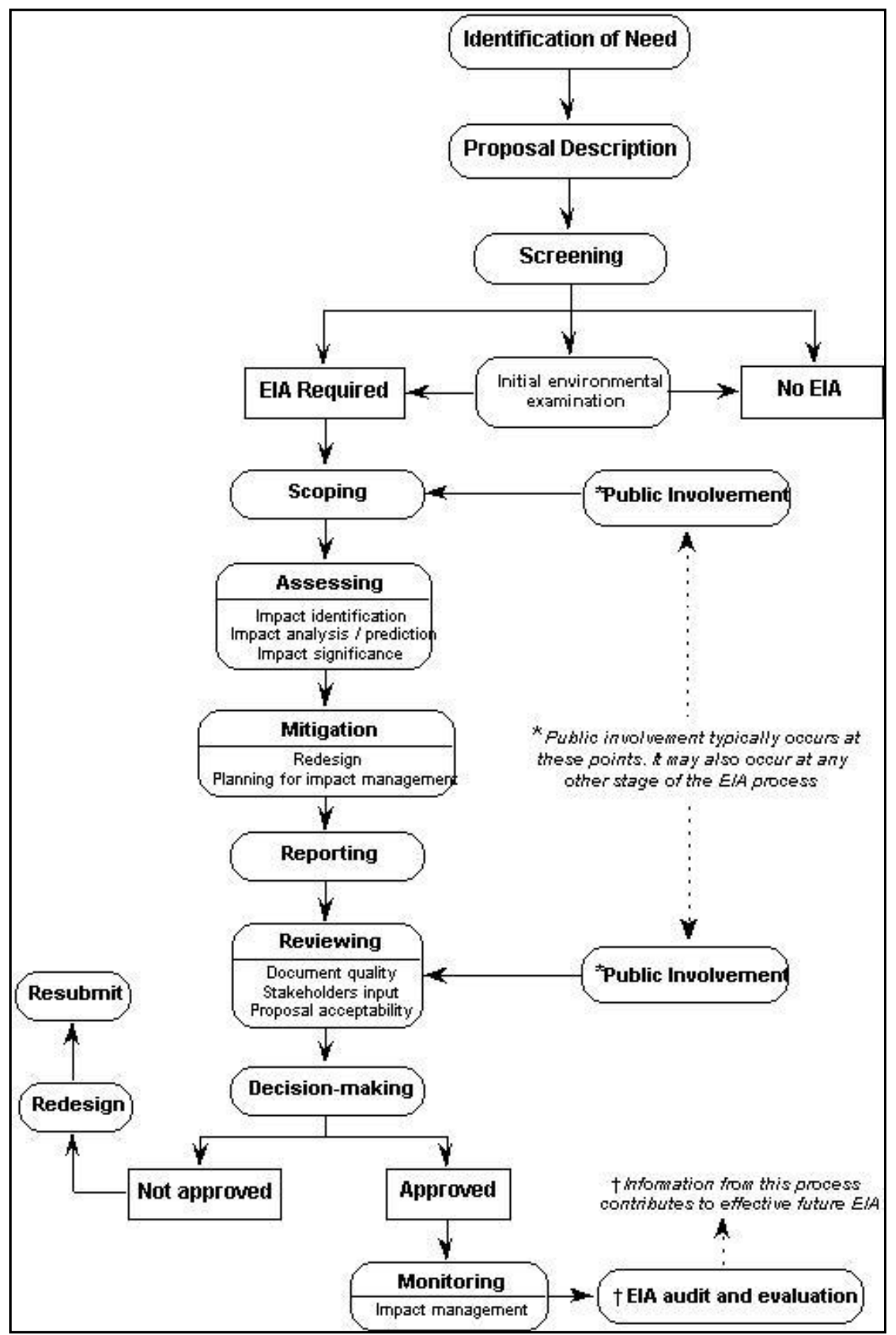

Figure 1: Environmental Impact Assessment Procedure Stages (Source: Sadler and McCabe, 2002[6]) 
Geographic Information Systems (GIS) As an Indispensable Tool for Environmental.....

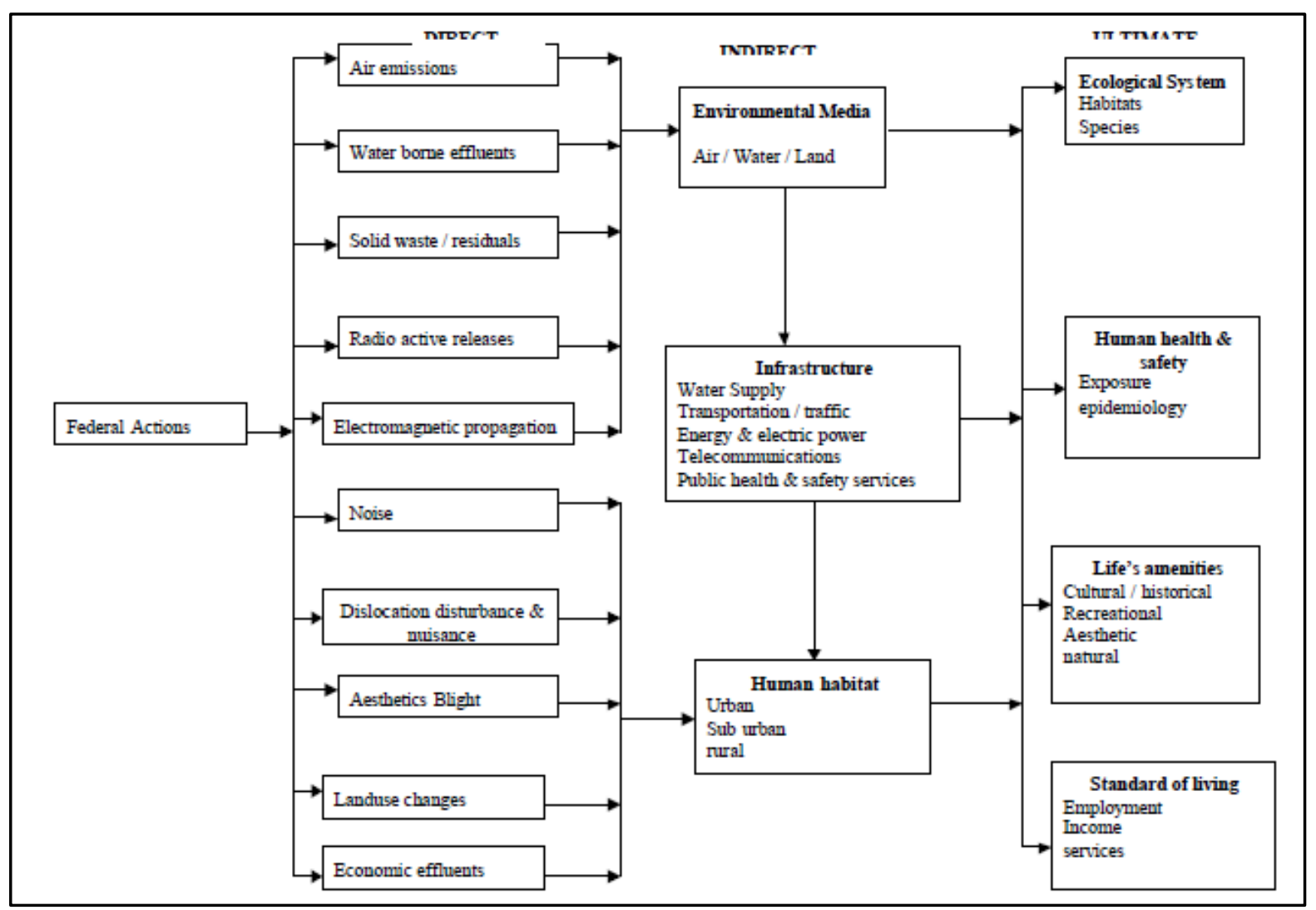

Figure 2: Systematic approach for impact identification (Source: Muthusamy and Ramalingam, 2003[3])

\section{Geographic Information Systems}

Geographic Information Systems are a set of tools for collecting, storing, retrieving at will, transforming and displaying spatial data from the world for a particular set of purposes (Burrough, 1986[7]). Longley et al (2005[8]) had several definitions of GIS and categorized these definitions according to disciplines, for instance, they stated that a GIS to the general public can be described as a container of maps in digital form, and that planners see it as a computerized tool for solving geographic problems, they went on to say that scientists and investigators see GIS as a tool for revealing what is otherwise invisible in geographic information and finally, resource managers and planners see GIS as a tool for performing operations on geographic data that are too tedious or expensive or inaccurate if performed by hand. The application of GIS is coherent with the discipline of the end users and has become applicable to nearly all human endeavours ranging from the simple task of finding best routes to complex data analysis and information extraction for best policy formulations.

Geographic Information System is essentially a marriage between computerized mapping and data base management systems (Yousefi, 2004[2]). GIS is entrenched in intellectual practices, populated by data and driven by mathematical analysis.

GIS uses layers also known as "themes" to overlay different forms of information, with each theme representing a category (in some cases categories) of information, such as population, roads, vegetation, settlements, forest cover, land use etc. Fig 3 shows how various layers put together can show a representation of the real world through a map.

A single map generally contains a lot of information which is used in different ways by different individuals and organisations. It represents a means of locating ourselves in relation to the world around us (Yousefi, 2004[2]). Maps are used in diverse applications; some of the uses include but are not limited to locating (a) point(s) of interest e.g. a street or a building or locating utilities such as electricity or telephone wires and gas pipelines, displaying the extent of deforestation in the Brazilian Amazon and the melting of a glacier in Iceland, finding wetlands that need protection from pollution, urban growth in Abuja etc. Yousefi (2004[2]) stated that, with a GIS hardware and software, maps usually display and analyse spatial data which most often have attributes which are tied to a database or databases. The ability for a system to have this connection is what gives GIS its power: maps can be drawn from the database and data can be referenced from the maps. When a database is updated, the associated map can be updated as well. GIS databases include a wide variety of information including geographic, social, political, environmental, and demographic. 


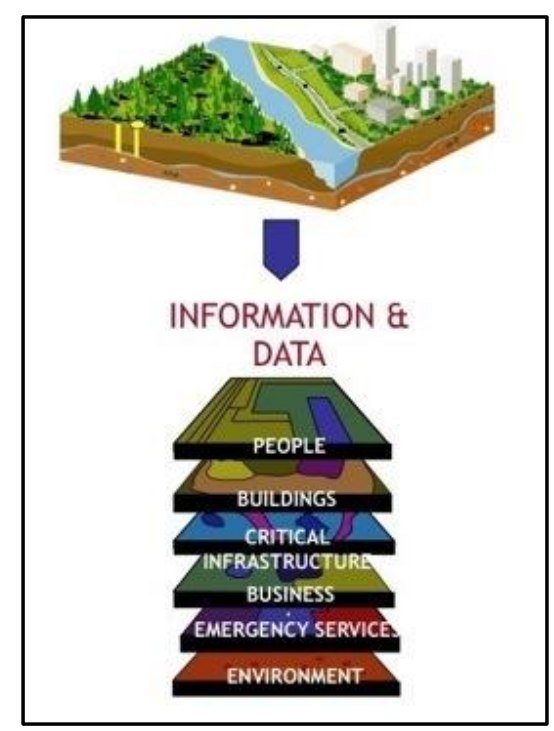

Figure 3: Data and Information comes from a set of layers (Source: Perez, 2012[9])

GIS provides the platform for an end user to extract different sets of information from a map to be used as required, thus providing a lot of flexibility to have a paper map which meets the exact needs of the end user to be produced in quick time. But this ability is only one of many, GIS goes further in its capabilities because the data are stored on a computer which then makes analysis and modelling become an easy task to execute. For Instance, GIS can be used by a community to identify a site(s) suitable for establishing cemeteries or waste disposal facilities simply by overlaying several spatial datasets which may include soil type, vegetation, ground water, surface water, geology, etc with specific assessment criteria and parameters for each layer to produce a map indicating areas considered suitable and unsuitable. So it is with capabilities such as these that GIS can play a significant role when it comes to making decisions about selecting sites for new roads, new waste facilities, geothermal site/ power plants, dams, carrying out EIA projects, protecting settlements from environmental hazards etc. GIS can merge with ease disjointed information into easily understood maps and can perform complicated analytical functions and then present the results visually as maps, tables or graphs, thereby allowing decision-makers to practically see the issues before them and then select the most suitable course of action.

In addition, remote sensing provides synoptic view of an object, area or phenomenon under EIA. Its ability to provide spatial datasets ranging from coarse to fine resolution with temporal resolution suitable for monitoring and evaluation of changes that resulted from a project or programme will make an EIA a robust tool to ensure protection of flora and fauna been the major target of any EIA.

\section{Application Of GIS In The Process Of EIA}

Given the spatial nature of many environmental impacts, Geographical Information Systems can have a wide application in all EIA stages, acting as an integrative framework for the entire process, from the generation, storage, and display of the thematic information relative to the vulnerability and/or sensitivity of the affected resources, to impact prediction and finally their evaluation for decision support (Antunes et al., 1996[10]).

Yousefi et al (2003[11]) stated that, EIA is a decision process, which aims to both identify and anticipate impacts on the natural environment. The interface between these two components produces several effects, which will generate specific impacts. GIS is employed within the EIA process to improve different features, mainly related to data storage and access, to the analytical capabilities and to the communicability of the results. The development of such a system will allow a more realistic approach to the environmental descriptors and a better understanding of their interrelationships. GIS brings to the EIA process a new way of analyzing and manipulating spatial objects and an improved way of communicating the results of the analysis, which can be of great importance during the public participation process where the results from the public consultation and social surveys can be imported into a GIS for spatial and non-spatial analysis, and display in a format that is easily understood by both technical and nontechnical stakeholders.

Erickson (1994[12]) identified four methodologies associated with EIA, each with its own strengths and weaknesses. The four methodologies are: Overlay, Checklist, Matrix and Network.

4.1 The Overlay method of impact assessment involves overlaying of various layers of interest of the study area to reach the desired goal. Some of the data this method requires include topological data, air dispersal 
patterns, land use data, wildlife, surface and ground water intakes etc. this method depends heavily on graphical display of data and as such GIS becomes the ultimate tool for overlay in EIA.

4.2 The Checklist method can be a very simple or complex list of environmental components attributes and processes, which are categorized under different categories e.g. Geology, vegetation and air. GIS provides a computer platform for organizing, storing and analyzing these checklists.

4.3 The Matrix method is the process of relating specific project activities to specific types of impacts. Matrices are required because they emphasize only direct impacts. They enforce the consideration of the impact of each aspect of a proposal for a range of environmental concerns and they consider both the magnitude and importance of impacts (Bhatt, 2009[1]). Again, GIS provides a powerful tool for organizing, analyzing and storing matrices.

4.4 The Network method defines a network of possible impacts that may be triggered by project activities. It also involves the identification of project actions along with the direct and indirect impacts. From the network methodology, direct, secondary, tertiary and other higher order impacts of action are to be identified. There is need for complex data analyses using this methodology and on a GIS platform large volumes of data can be better analysed within a short period of time.

Geographic Information Systems also have the capability for site impact prediction (SIP), wider area prediction (WAP), cumulative effect analysis (CEA), and environmental audits and for generating trend analysis within an environment (Fedra, 1993[13]).

Furthermore, Eedy (1995[14]) stresses some of the advantages of the use of GIS in EIA, namely for data management, overlay and analysis, trend analysis, as sources of data sets for mathematical impact models, habitat and aesthetic analysis, and public consultation. According to a survey undertaken by Joao and Fonseca (1996[15]), GIS were used for all EIA stages. The most frequent use was for the presentation of results, followed by analysis/modelling and data preparation. GIS have also been used for the presentation of environmental baseline information and project description, through the preparation of thematic maps for the several environmental descriptors. Also, the overlay of baseline information maps with project layouts is frequently used for impact identification (Joao and Fonseca, 1996[15]).

Table 1: EIA Stages and Application of GIS/RS in Each Stage (adapted from Joao and Fonseca, 1996[15]).

\begin{tabular}{|l|l|l|}
\hline S/No. & STAGE & POSSIBLE USAGE OF GIS \\
\hline 1 & Screening and Scoping & $\begin{array}{l}\text { GIS datasets overlay provides suitable tool for data analysis, data } \\
\text { gathering, spatial data modelling, calculation of impact magnitude }\end{array}$ \\
\hline 2 & Description of the project & Mapping of spatial extent of project (geographical context) \\
\hline 3 & Description of baseline conditions & $\begin{array}{l}\text { biophysical inventories, hydrology, soils, archaeological and historical } \\
\text { resources, land ownership, topography, roads, utilities }\end{array}$ \\
\hline 4 & Impact Identification & Overlay analysis, modelling, habitat suitability analysis \\
\hline 5 & Prediction of impact magnitude & $\begin{array}{l}\text { GIS predictive and modelling function - percentage change, impact } \\
\text { magnitude maps, risk maps, modelling results }\end{array}$ \\
\hline 6 & Assessment of impact significance & Map impact significance by alternative \\
\hline 7 & Impact mitigation and control & $\begin{array}{l}\text { GIS/RS to identify best mitigation measures or effectiveness of mitigation } \\
\text { strategies, spatially and/or temporally impacts. }\end{array}$ \\
\hline 8 & Public consultation and participation & $\begin{array}{l}\text { Preparation presentation material, to explain the project to the public, } \\
\text { responses to comments }\end{array}$ \\
\hline 9 & Monitoring and auditing & $\begin{array}{l}\text { Remote Sensing provides datasets for monitoring of environmental impacts } \\
\text { of projects/programme overtime. While GIS design monitoring programs, } \\
\text { processing and storage of monitoring data, comparison of actual outcomes } \\
\text { with predicted outcomes, impacts over time }\end{array}$ \\
\hline
\end{tabular}

\section{Case Studies For The Application Of GIS/RS In EIA}

5.1 GIS/RS for River Lower Niger Dredging: Abas and Ukoje (2009[16]) in their case study of the proposed dredging of lower Niger River from Warri (Delta State) through the Forcados/Warri River to Baro (Niger State). The entire stretch of the river to be dredged was $592 \mathrm{~km}$ in length. The EIA of the Forcados segment dredging on the area was conducted using Landsat TM (1994); topographic maps; vegetation and landuse/landcover maps of the area. The satellite image was georeferenced, processed and resampled for visualization in a GIS environment. Arch info 3.5.1 software was used for the analysis. After the analysis, the results obtained showed that a total of 17 settlements of about $6.03048 \mathrm{~km} 2(25 \%)$ of the total built up area will be impacted; 7 major roads covering $36.078 \mathrm{~km} 2(67 \%)$ out of $54.3616 \mathrm{~km} 2$ will be impacted; about $634.60708 \mathrm{~km} 2$ of various vegetation types will be impacted in the area. The analysis also showed that 7 fishing camps will also be lost thus an important means of livelihood will be destroyed. The analysis and results obtained in this process took only a matter of minutes 
5.2 Least Impact Corridor Selection: Zura and Lipar (1995[17]) undertook an Environmental impact assessment to find the least impact corridor and to select the best alignment alternative between two places in Slovenia using Arcinfo (ESRI GIS Software). The estimation of the environmental vulnerability was based on data gathered on the fauna, flora, soil, water, air, climate, landscape, natural and cultural environment, urban areas, etc. and the importance of the different phenomena within the study area. After all the data had been collected, and entered into the GIS package, a model was built to show the new road layout with alternatives showing their various levels of impact on the environment and ideally, the layout with the least impact was selected.

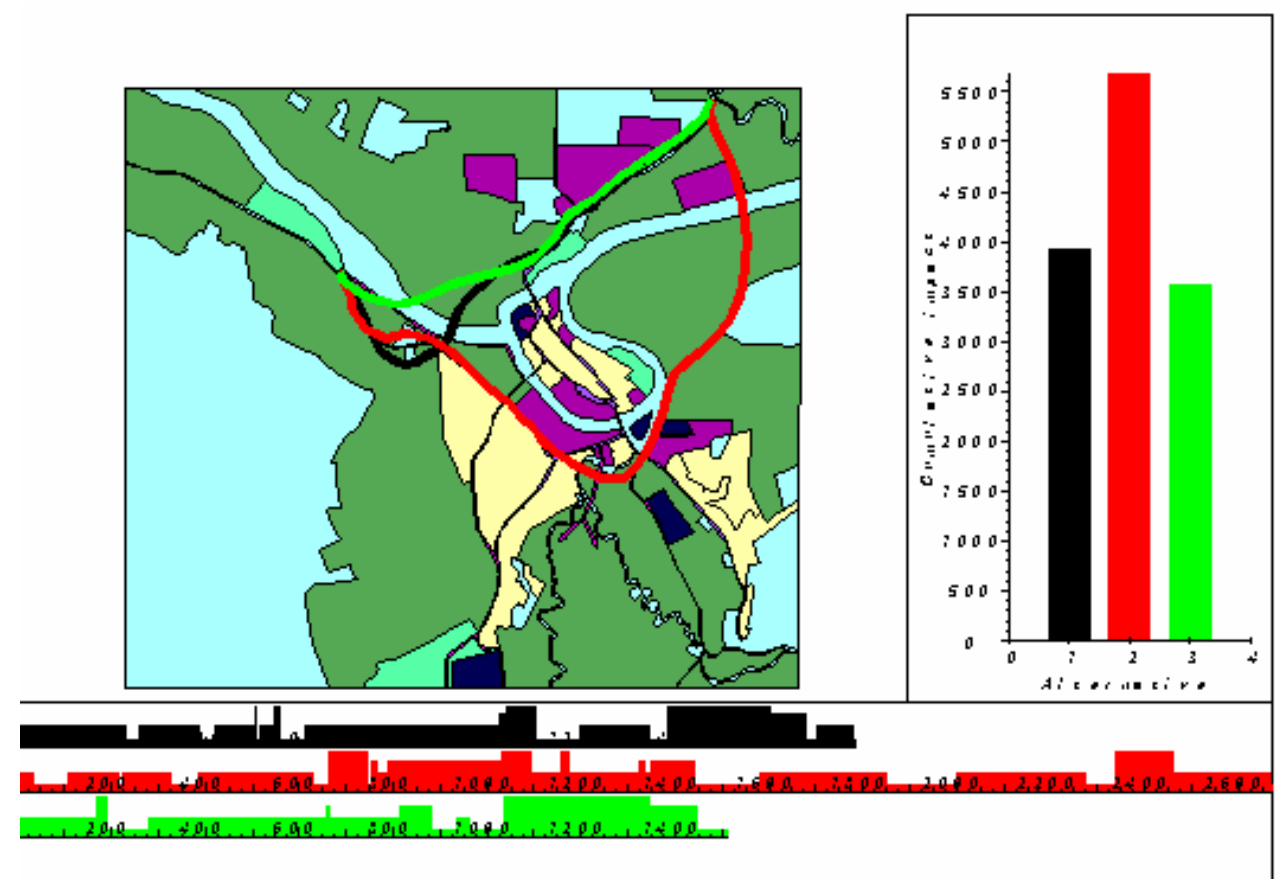

Figure 4: showing cumulative impacts of each alternative route (Source: Zura and Lipar, 1995).

\section{Conclusion}

Environmental impact assessment draws from evidence and is also informed by evidence, which in turn supports decision making and project implementation. One aspect of this evidence is clearly spatial, due to the intrinsic geographic nature of natural resource management and environmental planning (Campo, 2012[4]). Having stated this, it can be argued that spatial data and GIS have significant potential to support environmental impact assessment processes. GIS have the potential to boost the quality and quantity of information provided to decision-making. While satellite remote sensing is a reliable source of spatial datasets for EIA at every stage of the procedure from planning, implementation, evaluation and monitoring, critics usually point out that the costs associated with the development of a GIS database are sometimes an obstacle to their wider use in EIA. The cost becomes insignificant when compared with the benefits associated with impact mitigation measures and the benefits obtained from a better decision-making provided with the integration of GIS/RS in the process of EIA.

Studies have proven for a fact that GIS is indeed a necessary tool that should be adopted to aid in any EIA exercise due to the fact that a GIS is exceptionally efficient and convenient in collecting, managing and analyzing the data collected, identifying complex interrelationships between environmental characteristics and visualizing the results of an EIA which in most cases are displayed as images (including 2D and 3D maps) or figures which represent information in a compact way for easier comprehension. Furthermore, an integrated GIS/RS can be constantly and systematically updated so that changes over time can easily be evaluated and the data can be used for more than one project at a time.

Finally, on a GIS platform, it is possible to store large amounts of different kinds of data (spatial and non-spatial) on a GIS based database. Also, the database can easily be integrated with remote sensing data, which are dynamic and temporal by default, as a result of this, it can assist in an immense way to prepare environmental audits of the same project at a later stage.

\section{References}

[1]. Bhatt, R.P. (2009). The Need and Use of Geographic Information System for Environmental Impact Assessment in Nepal; Journal of Water Energy and Environment, Issue No (4) PP (29-31).

[2]. Yousefi, H. (2004). Application of GIS in the Environmental Impact Assessment of Sabalan Geothermal Fields, NW-Iran. Geothermal Training Programmes Reports, Reykjavik, Iceland. Report 19, pp. 439-474. 
[3]. Muthusamy, N. and Dr. M. Ramalingam (2003). "Environmental Impact Assessment For Urban Planning And Development Using Gis" in Martin J. Bunch, V. Madha Suresh and T. Vasantha Kumaran, eds., Proceedings of the Third International Conference on Environment and Healt h, Chennai, India, 15-17 December, 2003. Chennai: Department of Geography, University of Madras and Faculty of Environmental Studies, York University. Pages $290-299$.

[4]. Campo, A. G. D. (2012). GIS in Environmental Assessment: A Review of Current Issues and Future Needs, Journal of Environmental Assessment Policy and Management Vol. 14, No. 1, 1250007 (23 pages).

[5]. Agrawal, M.L. \& Dikshit, A.K., (2002). Significance of spatial data and GIS for Environmntal Impact Assessment of Highway Projects, Indian Cartographer, 4, 262.

[6]. Sadler, B. and McCabe, M (2002). Environmental Impact Assessment Training Resource Manual. UNEP. Geneva

[7]. Burrough, P A (1986). Principles of Geographical Information Systems for Land Resources Assessment. (Clarendon Press, Oxford.)

[8]. Longley, Paul A.; Goodchild, Michael F.; Maguire, David W. \& Rhind (2005). Geographic Information Systems and Science (2nd ed.) (England, John Wiley and sons Ltd).

[9]. Perez, Sergio (2012) Environmental Impact Assessment (EIA), GIS for Water Environmental Management at URL: http://watergis.wordpress.com/2012/03/20/environmental-impact-assessment-eia/ [Date Accessed: 09 October 2013]

[10]. Antunes, P., Santos, R. \& Jardao, L. (2001). The Application of Geographical Information System to determine environmental impact significance",Environmental Impact Assessment Review, Vol. 21,pp 511-535.

[11]. Yousefi, H., Noorollahi, Y., and Sohrab, T., (2003). Environmental Impact Assessment of Meshkinshahr geothermal power plant. Proceedings of the 4th National Energy Congress, 2003, Tehran, Iran, 210-219.

[12]. Erickson, P.A., (1994). A Practical Guide to Environmental Impact Assessment (New York: Academic Press).

[13]. Fedra K. (1993). GIS and environmental modelling. In: Goodchild, M.F., Parks, B.O., Steyaert, L.T., editors. Environmental modelling with GIS. (Oxford: Oxford Univ. Press. pp. 35- 50).

[14]. Eedy, W., (1995). The use of GIS in environmental assessment, in Impact Assessment (International Association for Impact Assessment, IAIA), 13(20): 199-206.

[15]. Joao, E. \& Fonseca, A. (1996). The role of GIS in improving environmental assessment effectiveness: theory vs practice. Impact Assess 1996;14:371-87.

[16]. Abbas, I. I., \& Ukoje, J. A. (2009). Application of Remote Sensing (RS) and Geographic Information Systems (GIS) to Environmental Impact Assessment (EIA) for sustainable development. Research Journal of Environmental and Earth Sciences, 1(1), 11-15.

[17]. Zura, M. and Lipar, P. (1995). .The Road and Traffic Environmental Impact Assessment and Optimal Room Layout Selection., ESRI user conference 1995 proceedings, http://www.esri.com/library/userconf/proc95to200/p157.html. 